\title{
МОРФОБИОЛОГИЧЕСКИЕ ОСОБЕННОСТИ, ПРОДУКТИВНОСТЬ И КАЧЕСТВО ДЕТЕРМИНАНТНЫХ ГИБРИДОВ ТОМАТА В ВЕСЕННИХ ТЕПЛИЦАХ РОСТОВСКОЙ ОБЛАСТИ
}

\author{
S.S. Avdeenko, T.N. Chumakova
}

\section{MORPHOBIOLOGICAL FEATURES, PRODUCTIVITY AND QUALITY OF DETERMINANT TOMATO HYBRIDS IN SPRING GREENHOUSES OF ROSTOV REGION}

\begin{abstract}
Авдеенко Светлана Сергеевна - канд. С.-х. наук, доц. каф. земледелия и технологии хранения растениеводческой продукции Донского государственного аграрного университета, Ростовская обл., Октябрьский р-н, п. Персиановский. E-mail: awdeenkoss@mail.ru

Чумакова Татьяна Николаевна - канд. пед. наук, доц. каф. экономики и менеджмента Донского государственного аграрного университета, Ростовская обл., Октябрьский р-н, п. Персиановский. E-mail: tana201025@mail.ru
\end{abstract}

Цель исследования - изучение и подбор детерминантных гибридов томата, пригодных для раннего и сверхраннего потребления. Задачи исследования: изучить морфоологические и биологические особенности гибридов томата; выявить лучшие по урожайности и качеству продукции детерминантные гибриды томата, пригодные для раннего и сверхраннего потребления. Объектом исследования были новые детерминантные гибриды томата, пригодные для раннего и сверхраннего потребления. Исследование проводилось с использованием лабораторно-полевого однофракторного опыта в условиях Ростовской области в 2018 г. Достоверность представленной работы подтверждается результатами исследований, проведенных в соответствии с основными методиками закладки и проведения полевых опытов, необходимым объемом сопутствующих наблюдений и учетов, достоверностью статистической обработки полученных экспериментальных данных и положительными результатами производственной проверки. На основе подробного изучения и оценки значительного числа гибридов томата в условиях ССЦ «Ростовский» выделены наиболее перспективные гибриды то-
Avdeenko Svetlana Sergeevna - Cand. Agr. Sci., Assoc. Prof., Chair of Agriculture and Technology of Crop Production Storage, Don State Agrarian University, Rostov Region, Oktyabrsky District, S. Persianovsky.

E-mail: awdeenkoss@mail.ru

Chumakova Tatyana Nikolaevna - Cand. Ped. Sci., Assoc. Prof., Chair of Economy and Management, Don State Agrarian University, Rostov Region, Oktyabrsky District, S. Persianovsky.

E-mail: tana201025@mail.ru

мата детерминантного типа, сочетающие хозяйственно полезные признаки с высокой урожайностью и раннеспелостью. Все изученные детерминантные гибриды томата значительно различались по скороспелости и срокам созревания. Наиболее скороспельми были гибриды Афрродита и Катя, которые также выделялись высотой и количеством листьев, превышающим контроль. Наибольшую урожайность показали варианты Афрро-

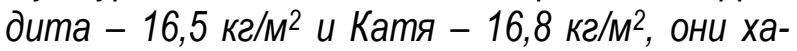
рактеризовались дружным плодоношением, высокими результатами качества продукции, формировали более ровные по размеру и форме плоды, с наименьшим числом семенных камер, равным 3. Больше всего сухих веществ оказалось в плодах гибрида Катя - 6,2 \%, а сахаров - в гибридах Катя и Aфрродита - 4,5 и 4,2 \% соответственно. Наиболее низкий показатель содержания нитратов был зафиксирован у гибрида Афрродита - 35,2 ме/ке.

Ключевые слова: детерминантные гибриды томата, весенняя теплица, раннее потребление, морфобиологические особенности, хозяйственно полезные признаки, продуктивность, качество. 
The main goal was to study and select determinant tomato hybrids suitable for early and late consumption. The research problems were to study morphological and biological features of hybrids of the tomato; to reveal the best ones on productivity and quality of production the determinant hybrids of the tomato suitable for early and superearly consumption. The new determinant hybrids of the tomato suitable for early and superearly consumption were the objects of the research. The research was conducted by using laboratory and field onefactorial experiment in the conditions of Rostov $\mathrm{Re}$ gion in 2018. The reliability of presented work was confirmed by the results of the researches conducted in accordance with the basic methods of laying and conducting field experiments, the necessary volume of accompanying observations and records, the reliability of statistical processing of the experimental data obtained and positive results of production check. On the basis of detailed studying and the assessment of considerable number of hybrids of the tomato in the conditions of $A C$ "Rostovsky" the most perspective hybrids of the tomato of determinant type combining economically useful signs with high productivity and early ripeness were allocated. All studied determinant hybrids of the tomato considerably differed in precocity and the terms of maturing. Hybrids Aphrodite and Katya which were also allocated with the height and quantity of leaves exceeding control were the earliest ones. The greatest productivity was shown by the variants Aphrodite $16.5 \mathrm{~kg} / \mathrm{sq} . \mathrm{m}$ and Katya $16.8 \mathrm{~kg} / \mathrm{sq} . \mathrm{m}$, they were characterized by amicable fructification, good results of the quality of production, formed more equal by the size and form of fruits, with the smallest number of seed chambers, equal to 3. Most of all solids it appeared in hybrid fruits Katya - $6.2 \%$, and sugars in hybrids Katya and Aphrodite - 4.5 and $4.2 \%$, respectively. The lowest indicator of the content of nitrates was recorded in the hybrid Aphrodite - $35.2 \mathrm{mg} / \mathrm{kg}$.

Keywords: determinant tomato hybrids, spring greenhouse, early consumption, morphobiological features, economically useful features, productivity, quality.

Введение. Одной из ценнейших овощных культур России является томат, годовая норма потребления которого на душу населения колеблется в пределах 25-32 кг плодов. Исключи- тельная ценность плодов томата заключается в том, что они содержат: витамины, органические кислоты, минеральные соли, необходимые для лучшего обмена веществ, повышения аппетита и сохранения трудоспособности человека. Содержание крайне полезных веществ и витаминов характеризует томаты как ценный продукт питания [1].

Существующее разнообразие сортов и гибридов не позволяет четко представить себе, каким образом выбрать нужный именно вам. При этом формы индетерминантные, полудетерминантные и детерминантые отличаются друг от друга кардинально. Выращивать детерминантные гибриды значительно проще. Они компактные, могут расти без подвязывания. Многие из них не нужно пасынковать. Их плоды созревают до массового распространения опасного заболевания - фитофтороза, поэтому требуют меньше обработок от болезней химическими средствами.

Цель исследования: изучение и подбор детерминантных гибридов томата, пригодных для раннего и сверхраннего потребления.

Задачи исследования: изучить морфологические и биологические особенности гибридов томата; выявить лучшие по урожайности и качеству продукции детерминантные гибриды томата, пригодные для раннего и сверхраннего потребления.

Изучению гибридов томата детерминантного типа для защищенного грунта посвящены исследования С.Ф. Гавриш $(1992,2003)$, Е.С. Балашова (2006), И.Н. Андреевой (2012), Т.А. Редичкиной (2016), К.Г. Прохоровой (2016) [2-7]. В последнее время среди большого многообразия гибридов возникла необходимость более подробного изучения культуры томата детерминантного типа развития, выявления гибридов ранних сроков созревания и получения ультрараннего урожая в условиях весенних теплиц Ростовской области.

Объекты и методы исследования. Опыт лабораторно-полевой, однофакторный проводился в условиях ССЦ «Ростовский» Октябрьского района Ростовской области. Посевная

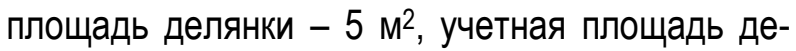
лянки - 2 м². Размещение вариантов опыта систематическое ярусное в 4-кратной повторности. Объектом исследования были детерминантные 
гибриды томата, пригодные для раннего и сверхраннего потребления. Стандарт - гибрид Андромеда, рекомендованный к использованию в Ростовской области. Изучение проводилось в 2018 г. согласно Методике полевого опыта в овощеводстве [8]. Проводились фенологические наблюдения, рассчитывалась продолжительность межфазных периодов, отмечалась динамика ростовых процессов. Учет урожая осуществлялся весовым методом, учитывались сроки начала поступления урожая, средняя масса и количество плодов на растении, содержание сухих веществ по ресрактометру и другие показатели. Урожайные данные обрабатывались методом дисперсионного анализа с применением ЭВМ.

Результаты исследования. Географическое положение России не способствует равномерному поступлению свежей овощной продукции, которое подвержено ярко выраженной сезонности потребления. Вследствие чего значительные объемы свежих овощей завозятся по импорту из-за рубежа. Прежде всего, это касается теплолюбивых овощных культур, таких как томат, перец, огурец.

В условиях юга России и Ростовской области в частности вполне возможно получать дешевую качественную овощную продукцию, которая по цене и качеству могла бы конкурировать с овощами, завезенными из-за рубежа. Решить эту проблему возможно путем развития овощеводства защищенного грунта, и, в частности, выращивания теплолюбивых овощных культур в весенних необогреваемых теплицах. Организация подобного производства является экономически выгодной, о чем свидетельствует опыт многочисленных мелких фрермерских хозяйств в регионе.

Основная причина низких урожаев овощей в наших тепличных комбинатах - возделывание малопродуктивных сортов и гибридов, нарушение технологии минерального питания растений и защиты их от болезней и вредителей. Продуктивность растений томата зависит также от типа почв, их плодородия и возделываемых сортов и гибридов. А возможности современной селекции предлагают широкий выбор адаптированных гибридов.

Так, наибольшую популярность на юге России, прежде всего в Краснодарском крае и республиках Северного Кавказа, приобрел гибрид $\mathrm{F}_{1}$ Персиановский. Растения этого гибрида имеют детерминантный мощный куст, хорошо облиственный. Листья отличаются интенсивной окраской и толстой кутикулой. От всходов до начала созревания проходит всего 100-105 дней, т. е. гибрид принадлежит к ранней группе спелости [9].

Производство ранней продукции без выращивания рассады невозможно. Для этого используются специальные разводочные теплицы небольшого объема, оборудованные системой обогрева, досвечивания, а процесс выращивания рассады, как правило, не только технологически, но и технически обособлен от других этапов производства. Качество рассады, а также сроки ее производства - залог получения в дальнейшем ранних и высоких урожаев продукции, особенно для детерминантных гибридов, предназначенных для получения раннего и сверхраннего потребления (табл. 1).

Таблища 1

\section{Продолжительность межфазных периодов у изученных гибридов томата}

\begin{tabular}{|l|c|c|c|c|}
\hline \multirow{2}{*}{ Образец } & \multicolumn{4}{|c|}{ Продолжительность периода, дней } \\
\cline { 2 - 5 } & $\begin{array}{c}\text { Всходы- } \\
\text { цветение }\end{array}$ & $\begin{array}{c}\text { Цветение- } \\
\text { созревание }\end{array}$ & $\begin{array}{c}\text { Всходы- } \\
\text { созревание }\end{array}$ & Плодоношения \\
\hline 1 & 2 & 3 & 4 & 5 \\
\hline Андромеда - (стандарт) & 50 & 60 & 110 & 65 \\
\hline Персиановский & 49 & 54 & 103 & 52 \\
\hline Государь & 46 & 53 & 99 & 47 \\
\hline Премиум & 47 & 53 & 100 & 34 \\
\hline Донской & 44 & 44 & 88 & 33 \\
\hline Афродита & 42 & 40 & 82 & \\
\hline
\end{tabular}


Окончание табл. 1

\begin{tabular}{|l|c|c|c|c|}
\hline \multicolumn{1}{|c|}{1} & 2 & 3 & 4 & 5 \\
\hline Маршал & 45 & 45 & 90 & 40 \\
\hline Изящный & 47 & 58 & 105 & 45 \\
\hline Раздолье & 45 & 50 & 95 & 34 \\
\hline Ловкий & 46 & 47 & 93 & 37 \\
\hline Аксинья & 48 & 50 & 98 & 35 \\
\hline Катя & 40 & 40 & 80 & 32 \\
\hline
\end{tabular}

Продолжительность межфразных периодов и общий вегетационный период являются обычно сортовыми признаками, но в том числе зависят от конкретного места выращивания и условий выращивания (состав почвогрунта, климат, срок посева, элементов технологии выращивания и др.). Так, наиболее рано началось цветение у гибридов Катя и Афрродита - 40-42 дня (см. табл. 1). Период от всходов до созревания данных гибридов составил соответственно 82 и 80 дней, и это первые гибриды, которые дали самый ранний урожай. С другой стороны, и это тоже закономерно для скороспелой группы гибридов, период активной отдачи продукции очень компактный и составляет всего 32-33 дня. Важным является также срок начала созревания продукции. Так, всего через 40 дней после начала цветения у гибридов Афродита и Катя начинается созревание первых плодов, естественно в первой цветочной кисти. После начала цветения остальные гибриды в опыте начинают давать технически зрелые плоды через 44-60 дней, что на 4-20 дней позднее гибридов Катя и Афродита.

Отсюда следует, что, имея набор гибридов с растянутым сроком начала цветения (через 4050 дней), еще более продолжительным периодом до начала созревания первых плодов (40-60 дней) можно спроектировать конвейер поступления свежих плодов томата из весенних грунтовых теплиц, который будет покрывать период по- требности в данной продукции минимум на 2 месяца, давая возможность обеспечения населения 5-й световой зоны свежей продукцией местного производства с высоким качеством (в том числе экологически безопасной) еще до начала поступления такой продукции из открытого грунта.

Учитывая высокую потребность в ранней продукции местного производства, нужно особо обратить внимание на гибриды, которые и рано начинают созревать, и имеют короткий период плодоношения. Такими характеристиками, на основании наших данных, можно считать несколько гибридов - это гибриды Катя, Афрродита, кроме этого, достаточно близкие показатели у гибрида Донской, и, следовательно, его тоже можно отнести к ультраскороспелым. Позже всех переходят к созреванию плодов гибриды Премиум, Персиановский, Изящный и стандарт - гибрид Андромеда, при этом данные гибриды отдают урожай на протяжении 44-65 дней, а это почти вдвое больше, чем ультраскороспелая группа, однако эти гибриды не отличаются высокой ценой.

Bce изученные гибриды томата имели детерминантный тип роста, а первая цветочная кисть закладывалась в большинстве вариантов над 5-7-м листом, хотя отдельные растения гибридов Катя и Афродита закладывали цветочные кисти над 4-5-м листом, что тоже ведет к раннему созреванию завязавшихся плодов (табл. 2).

\section{Морфологические признаки растений гибридов томата}

Таблица 2

\begin{tabular}{|l|c|c|c|c|}
\hline \multicolumn{1}{|c|}{ Образец } & $\begin{array}{c}\text { Высота рас- } \\
\text { тений, см }\end{array}$ & $\begin{array}{c}\text { Длина } \\
\text { междоузлий, см }\end{array}$ & $\begin{array}{c}\text { Высота заложения } \\
\text { 1 цветочной кисти, лист }\end{array}$ & $\begin{array}{c}\text { Обще кол-во } \\
\text { листьев, шт. }\end{array}$ \\
\hline \multicolumn{1}{|c|}{$\begin{array}{l}\text { Андромеда } \\
\text { (стандарт) }\end{array}$} & 75 & 3 & 4 & 5 \\
\hline Персиановский & 77 & 5,7 & $5-7$ & 78 \\
\hline Государь & 65 & 4,8 & $5-7$ & 73 \\
\hline
\end{tabular}




\begin{tabular}{|l|c|c|c|c|}
\hline \multicolumn{1}{|c|}{1} & 2 & 3 & 4 & Окончание табл. 2 \\
\hline Премиум & 63 & 4,4 & $5-6$ & 91 \\
\hline Донской & 65 & 4,2 & $5-7$ & 88 \\
\hline Афродита & 57 & 4,0 & $5-6$ & 99 \\
\hline Маршал & 85 & 4,6 & $5-6$ & 87 \\
\hline Изящный & 88 & 5,3 & $5-7$ & 74 \\
\hline Раздолье & 68 & 4,9 & $5-7$ & 93 \\
\hline Ловкий & 75 & 4,7 & $5-7$ & 85 \\
\hline Аксинья & 89 & 5,1 & $5-6$ & 96 \\
\hline Катя & 60 & 4,3 & $5-6$ & 104 \\
\hline
\end{tabular}

Изучаемые в опыте гибриды характеризовались детерминантным типом развития растений. В нашем опыте наиболее компактными были гибриды Афродита и Катя, высота которых составила соответственно 57 и 60 см при минимальной величине расстояния между последующими листьями (4,0-4,3 см), а количество листьев, образовавшихся за весь период вегетации, - 99 и 104 шт. У стандарта Андромеда в конце вегетации высота главного стебля составила $75 \mathrm{~cm}$, а количество листьев - 78 шт. Наибольшую высоту имели гибриды Изящный и Аксинья - 88-89 см соответственно.
Bсе изученные гибриды имели простое соцветие, а как известно, растения с простыми соцветиями имеют более высокую урожайность и выровненную массу плода. По длине соцветия отличились образцы Афрродита и Катя - 11,5 и 11,4 см соответственно. Наибольшее количество цветков в соцветии наблюдалось у гибрида Афрродита - 6-7 шт., наименьшее количество зафиксировано у гибрида Маршал - 3-4 шт. Длина цветочной кисти стандарта Андромеды составила 10,2 см, количество цветков в соцветии всего 3-5 шт. (табл. 3).

Таблица 3

\section{Морфологические признаки соцветий и плодов гибридов томата}

\begin{tabular}{|l|c|c|c|c|c|}
\hline \multicolumn{1}{|c|}{ Образец } & $\begin{array}{c}\text { Длина } \\
\text { соцве- } \\
\text { тия, см }\end{array}$ & $\begin{array}{c}\text { Количество } \\
\text { цветков } \\
\text { воцветии, шт. }\end{array}$ & $\begin{array}{c}\text { Масса } \\
\text { плода, г }\end{array}$ & Форма плода & $\begin{array}{c}\text { Камерность } \\
\text { плода, шт. }\end{array}$ \\
\hline $\begin{array}{l}\text { Андромеда } \\
\text { (стандарт) }\end{array}$ & 10,2 & $3-5$ & 130 & Округлая & 5 \\
\hline Персиановский & 9,8 & $4-5$ & 250 & Округлая & 6 \\
\hline Государь & 9,9 & $3-5$ & 165 & $\begin{array}{c}\text { Округлая с носиком } \\
\text { на вершине }\end{array}$ & 6 \\
\hline Премиум & 10,5 & $5-6$ & 140 & $\begin{array}{c}\text { Округлая с носиком } \\
\text { на вершине }\end{array}$ & 5 \\
\hline Донской & 10,1 & $4-5$ & 138 & $\begin{array}{c}\text { Округлая с носиком } \\
\text { на вершине }\end{array}$ & 5 \\
\hline Афродита & 11,5 & $6-7$ & 115 & Округлая & 3 \\
\hline Маршал & 9,6 & $3-4$ & 173 & Округлая & 7 \\
\hline Изящный & 10,4 & $4-5$ & 193 & Округлая & 9 \\
\hline Раздолье & 11,1 & $5-6$ & 230 & Округлая & 7 \\
\hline Ловкий & 9,3 & $3-5$ & 280 & Округлая & 7 \\
\hline Аксинья & 9,5 & $4-6$ & 145 & Округлая & 4 \\
\hline Катя & 11,4 & $5-6$ & 130 & Округлая & 3 \\
\hline
\end{tabular}


Как видно из данных таблицы 3, все изученные гибриды томата имели округлую форму плода, лишь у некоторых (Государь, Премиум, Донской) присутствовал так называемый «носик», который у потребителей пользуется большой популярностью. Наиболее мелкие плоды формировали образцы Андромеда, Катя - 130 г и Афрродита - 115 г, наиболее крупные наблюдались у образцов Персиановский, Раздолье и Ловкий - соответственно 250, 230 и 280 г. В нашем эксперименте наименьшее число камер имели плоды гибридов Афродита и Катя - 3 шт., наибольшее - гибрид Изящный - 9 шт. При этом если окраска незрелого плода у всех, конечно, была зеленая, то к моменту созревания только гибрид Персиановский характеризовался розовыми плодами.

Важнейшими составляющими урожайности томата являются такие элементы продуктивности, как число кистей, плодов в кисти, масса одного плода, на основании которых и была рассчитана урожайность (табл. 4).

Урожайность гибридов томата

Таблица 4

\begin{tabular}{|c|c|c|c|c|c|c|c|c|c|}
\hline \multirow{2}{*}{ Образец } & \multicolumn{2}{|c|}{ Урожай, кг/м² } & \multicolumn{7}{|c|}{ Доля от общего урожая, \% } \\
\hline & ранний & общий & 10.07 & 20.07 & 30.07 & 10.08 & 20.08 & 30.08 & 10.09 \\
\hline Андромеда (стандарт) & 2,0 & 10,0 & 20 & 20 & 20 & 20 & 20 & - & - \\
\hline Персиановский & 4,3 & 14,5 & 30 & 30 & 20 & 10 & 10 & - & - \\
\hline Государь & 2,6 & 13,2 & 20 & 20 & 20 & 30 & 10 & - & - \\
\hline Премиум & 3,5 & 14,0 & 25 & 20 & 15 & 15 & 10 & 15 & \\
\hline Донской & 3,8 & 12,8 & 30 & 30 & 25 & 15 & - & - & - \\
\hline Афрродита & 5,0 & 16,5 & 30 & 30 & 30 & 10 & - & - & - \\
\hline Маршал & 4,5 & 15,0 & 30 & 30 & 20 & 20 & - & - & - \\
\hline Изящный & 1,2 & 12,0 & 10 & 15 & 20 & 20 & 20 & 15 & - \\
\hline Раздолье & 3,2 & 15,8 & 20 & 20 & 25 & 25 & 10 & - & - \\
\hline Ловкий & 1,5 & 15,1 & 10 & 15 & 20 & 25 & 15 & 10 & 10 \\
\hline Аксинья & 3.0 & 15,0 & 20 & 20 & 25 & 20 & 15 & - & - \\
\hline Катя & 3,4 & 16,8 & 20 & 20 & 20 & 20 & 20 & - & - \\
\hline $\mathrm{HCP}_{05}$ & 1,36 & 2,48 & & & & & & & \\
\hline
\end{tabular}

* Ранний урожай - за первые 10 дней плодоношения.

Рассмотренные нами новые гибриды томата превысили стандарт по урожайности. Массовое созревание гибридов началось в июле месяце. В первой декаде июля ранняя урожайность была высокой у гибрида Афродита и составила 5 кг/M², что значительно превысило стандарт (в 2,5 раза), ранняя урожайность которого составила $2 \mathrm{\kappa r} / \mathrm{M}^{2}$. Среди изученных гибридов самыми урожайными были Афродита - 16,5 кг/м²

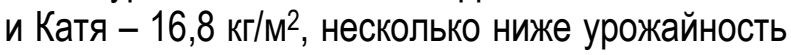
у гибридов Государь - 13,2 кг/м² и Донской 12,8 кг/M². Самые низкие показатели урожайности наблюдались у стандарта Андромеда $10 \mathrm{\kappa г} / \mathrm{M}^{2}$ и Изящный - $12 \mathrm{kг} / \mathrm{M}^{2}$. Сроки плодоношения у изученных гибридов заметно различались. Очень дружным было плодоношение у стандарта Андромеда, гибридов Катя и Афродита. Сильно варьировала урожайность с июля по сентябрь у гибридов Персиановский, Преми- ум и Ловкий. Относительно стабильным за весь период вегетации было плодоношение у гибридов Андромеда и Катя. Самый высокий урожай за июль месяц получен у гибрида Афродита.

В зависимости от условий выращивания химический состав овощей, их питательная и лечебная ценность сильно изменяются. Качество овощей существенно зависит от сорта, почвы, климатических условий, севооборота, применения удобрений, орошения, густоты стояния растений, сроков посева и уборки, условий хранения и переработки продукции, а также от многих других фракторов (табл. 5). Из данных таблицы 5 видно, что все изученные гибриды, также как и стандарт, имели высокую товарность урожая, и она находилась в интервале от 90,0 \% у гибрида Андромеда до 98,7-99,4 \% у гибридов Маршал, Катя и Афродита. 
Качество урожая детерминантных гибридов томата

\begin{tabular}{|l|c|c|c|c|c|c|}
\hline \multicolumn{1}{|c|}{ Образец } & $\begin{array}{c}\text { Товарность } \\
\text { урожая, \% }\end{array}$ & $\begin{array}{c}\text { Сухое веще- } \\
\text { ство, \% }\end{array}$ & $\begin{array}{c}\text { Общий } \\
\text { сахар, \% }\end{array}$ & $\begin{array}{c}\text { Общая } \\
\text { кислот- } \\
\text { ность, \% }\end{array}$ & $\begin{array}{c}\text { Сахаро- } \\
\text { кислотный } \\
\text { индекс }\end{array}$ & $\begin{array}{c}\text { Нитраты, } \\
\text { мг сырой } \\
\text { массы }\end{array}$ \\
\hline Андромеда (стандарт) & 90,0 & 5,1 & 3,3 & 0,55 & 5,8 & 61,2 \\
\hline Персиановский & 97,9 & 5,2 & 2,8 & 0,56 & 6,3 & 58,7 \\
\hline Государь & 98,5 & 5,3 & 2,9 & 0,48 & 5,2 & 45,2 \\
\hline Премиум & 96,4 & 5,4 & 3,0 & 0,49 & 6,4 & 45,9 \\
\hline Донской & 95,3 & 5,2 & 3,6 & 0,57 & 5,5 & 56,7 \\
\hline Афродита & 99,4 & 5,8 & 4,2 & 0,43 & 8,2 & 35,2 \\
\hline Маршал & 98,7 & 5,3 & 2,9 & 0,56 & 6,7 & 67,6 \\
\hline Изящный & 97,5 & 5,7 & 4,0 & 0,54 & 6,8 & 63,4 \\
\hline Раздолье & 98,1 & 5,2 & 2,7 & 0,57 & 6,6 & 48,7 \\
\hline Ловкий & 98,0 & 5,5 & 3,7 & 0,57 & 5,7 & 59,7 \\
\hline Аксинья & 96,7 & 5,0 & 2,5 & 0,45 & 7,1 & 39,1 \\
\hline Катя & 98,8 & 6,2 & 4,5 & 0,44 & 7,8 & 38,3 \\
\hline
\end{tabular}

Оценка содержания сухих веществ показала, что больше всего их в плодах гибрида Катя $6,2 \%$. Гибриды Катя и Афродита отличились большим содержанием сахаров - 4,5 и 4,2 \% соответственно, что больше стандарта Андромеда на 0,9-1,2 \%. Самое высокое значение сахаро-кислотного индекса имел гибрид Афродита - 8,2, а самое низкое с минимальной разницей - 5,0-5,2 гибриды Аксинья, Андромеда, Персиановский, Донской и Раздолье. В целом накопление нитратов в плодах томата характеризовалось невысокими показателями. Наиболее низкое содержание нитратов было зафиксировано у гибрида Афрродита - 35,2 мг/кг, что значительно ниже, чем предельно допустимая концентрация (ПДК) в плодах томатов закрытого грунта, равная 300 мг/кг свежей продукции.

Выводы. На основании проведенного исследования по оценке морфобиологических признаков, продуктивности и качества 12 гибридов томата детерминантного типа можно сказать, что лучшими являются гибриды Афродита и Катя, которые могут быть рекомендованы для выращивания в защищенном грунте в условиях Ростовской области. Результаты, полученные в процессе исследования, позволяют использовать их в учебном процессе и реализации педагогических технологий в условиях ФГОС высшего образования.

\section{Литература}

1. Гавриш С.Ф., Галкина С.Н. Томаты: Возделывание и переработка. М.: Росагропромиздат, $1990.190 \mathrm{c}$.

2. Балашов Е.С. Особенности роста и развития новых гибридов томата при выращивании в продленном обороте зимних остекленных теплиц: автореф. дис. ... канд. с.-х. наук. М., 2006. $18 \mathrm{C}$.

3. Гавриш С.Ф. Биологический потенциал культурного томата (Lycopersicon esculentum Mill.) и его использование в селекции для защищенного грунта: дис. ... д-ра с.-х. наук: 06.01.05. СПб., 1992. $89 \mathrm{c}$.

4. Гавриш С.Ф., Король В.Г., Шульгин И.А. Светотребовательность новых гибридов томата при выращивании в продленном обороте зимних теплиц // Гавриш. 2003. № 3. C. 13-19.

5. Андреева И.Н. Приемы выращивания и особенности семеноводства томата детерминантного типа в пленочных теплицах в условиях северо-запада РФ: дис. ... канд. с.-Х. наук: 06.01.01. СПб., 2012. 160 с.

6. Редичкина Т.А. Селекция крупноплодных гибридов томата с яйцевидной формой плода для защищенного грунта и элементы технологии их выращивания: дис. ... канд. 
с.-х. наук: 06.01.05, 06.01.09. М., 2016. $152 \mathrm{c}$.

7. Прохорова К.Г. Изучение и оценка исходного материала для селекции гибридов $\mathrm{F}_{1}$ томата с полудетерминантным типом роста: автореф. дис. ... канд. с.-х. наук: 06.01.05. M., 2016. $31 \mathrm{c}$.

8. Литвинов С.С. и др. Методика полевого опыта в овощеводстве. М.: Россельхозакадемия ВНИИО, 2011. 648 с.

9. Огнев В.В., Чернова Т.В., Костенко А.Н. и др. Розовоплодный гибрид томата $F_{1}$ Персиановский в открытом грунте на юге России // Картофель и овощи. 2018. № 11. C. 20-21.

\section{Literatura}

1. Gavrish S.F., Galkina S.N. Tomaty: Vozdelyvanie i pererabotka. M.: Rosagropromizdat, 1990. $190 \mathrm{~s}$.

2. Balashov E.S. Osobennosti rosta i razvitija novyh gibridov tomata pri vyrashhivanii $\mathrm{v}$ prodlennom oborote zimnih osteklennyh teplic: avtoref. dis. ... kand. s.-h. nauk. M., 2006. $18 \mathrm{~s}$.

3. Gavrish S.F. Biologicheskij potencial kul'turnogo tomata (Lycopersicon esculentum Mill.) i ego ispol'zovanie $v$ selekcii dlja zashhishhennogo grunta: dis. ... d-ra s.-h. nauk: 06.01.05. SPb., 1992. 89 s.

4. Gavrish S.F., Korol' V.G., Shul'gin I.A. Svetotrebovatel'nost' novyh gibridov tomata pri vyrashhivanii $\mathrm{v}$ prodlennom oborote zimnih teplic // Gavrish. 2003. № 3. S. 13-19.

5. Andreeva I.N. Priemy vyrashhivanija i osobennosti semenovodstva tomata determinantnogo tipa $v$ plenochnyh teplicah $v$ uslovijah severo-zapada RF: dis. ... kand. s.-h. nauk: 06.01.01. SPb., 2012. $160 \mathrm{~s}$.

6. Redichkina T.A. Selekcija krupnoplodnyh gibridov tomata s jajcevidnoj formoj ploda dlja zashhishhennogo grunta i jelementy tehnologii in vyrashhivanija: dis. ... kand. s.-h. nauk: 06.01.05, 06.01.09. M., 2016. $152 \mathrm{~s}$.

7. Prohorova K.G. izuchenie i ocenka ishodnogo materiala dlja selekcii gibridov F1 tomata $\mathrm{S}$ poludeterminantnym tipom rosta: avtoref. dis. ... kand. s.-h. nauk: 06.01.05. M., 2016. 31 s.

8. Litvinov S.S. i dr. Metodika polevogo opyta v ovoshhevodstve. M.: Rossel'hozakademija VNIIO, 2011. $648 \mathrm{~s}$.

9. Ognev V.V., Chernova T.V., Kostenko A.N. i dr. Rozovoplodnyj gibrid tomata F1 Persianovskij v otkrytom grunte na juge Rossii // Kartofel' i ovoshhi. 2018. № 11. S. 20-21. 